\title{
TEORIZANDO A PRÁTICA OU PRATICANDO A TEORIA? OS DESLOCAMENTOS IDENTITÁRIOS DE DUAS PROFESSORAS DE INGLÊS EM UM GRUPO DE PESQUISA-AÇÃO
}

\author{
THEORIZING PRACTICE OR PRACTICING THEORY? \\ THE IDENTITY SHIFTS EXPERIENCED BY TWO ENGLISH TEACHERS \\ WITHIN AN ACTION RESEARCH PROJECT
}

\author{
VALDENI DA SILVA REIS*,1 \\ LUCIENNE DE CASTRO SILVA** \\ ANA MÁRCIA MELO SOARES TORRES ${ }^{* * *}$
}

\begin{abstract}
RESUMO: O presente trabalho investiga alguns deslocamentos identitários vivenciados por duas professoras de inglês da rede pública de ensino do estado de Minas Gerais em um grupo de pesquisa-ação. Objetivamos explorar como a pesquisa-ação, desenvolvida pelas professoras, conjuga teoria e prática, ao mesmo tempo em que as impulsiona a se (re)descobrir de forma responsável em seu fazer pedagógico. Para tanto, são analisados excertos de diários escritos pelas professoras ao longo do ano em que desenvolveram a pesquisa-ação. A metodologia utilizada é a análise discursiva ancorada, sobretudo, pelo uso das Ressonâncias Discursivas (SERRANIINFANTI, 2001). Investigamos os deslocamentos identitários das professoras a partir de suas representações sobre o significado de ser professora, assim como suas expectativas de fazer parte de um curso de formação continuada. Analisamos, por fim, a forma com que as relações estabelecidas no grupo de pesquisa-ação deslocam a identidade dessas professoras em um processo dinâmico de descobertas e reorganização pedagógica.

Palavras-chave: pesquisa-ação; identidade; identificação; relações; representações
\end{abstract}

\begin{abstract}
This paper investigates identity shifts experienced by two English teachers from the public school system in the state of Minas Gerais, within an action-research group. It aims at exploring how the actionresearch project, which was developed by these teachers, joins together theory and practice, encouraging them to (re)discover themselves and to take responsibility for their pedagogical practice. We analyze excerpts of the teachers' journals written throughout the year that they developed the action-research. The methodology is based on Discourse Analysis, particularly the Discursive Resonances categories (SERRANI-INFANTI, 2001). We investigate the teachers' identity shifts regarding their representations of the meaning of being a teacher, as well as their expectations of the continuing education program in which they take part. Finally, we examine in which sense the relationships established among the action-research team promote identity shifts in a dynamic process of discovering and reorganizing their teaching practice.
\end{abstract}

Keywords: action research; identity; identification; relationships; representations

* UFMG, Belo Horizonte (MG), Brasil. valdeni.reis@gmail.com

** EESS-Escola Estadual São Sebastião, Belo Horizonte (MG), Brasil.

lucienne.decastro@yahoo.com.br

*** EMCDA-Escola Municipal Carlos Drummond de Andrade/FUNEC-Fundação de Ensino de Contagem, Contagem (MG), Brasil. iumatorres@bol.com.br

${ }^{1} \mathrm{O}$ presente trabalho foi realizado com o apoio do Conselho Nacional de Desenvolvimento Científico e Tecnológico - CNPq - Brasil. 


\section{INTRODUÇÃO}

Nos últimos anos, pudemos perceber uma preocupação crescente com a discussão e integração entre a teoria acadêmico-educacional desenvolvida nas universidades e a prática dos professores nas salas de aula.

Nessa direção, surgem por todo o Brasil cursos de Educação Continuada ${ }^{2}$ (EC), no intuito de estabelecer parcerias que integrem questões trazidas por professores, principalmente da rede pública de ensino, às metodologias desenvolvidas nas universidades.

Educação ou formação continuada consiste em iniciativas teórico-metodológicas de formação, oferecidas geralmente por instituições de ensino superior, ao professor em serviço. Tais iniciativas são vistas pelos professores e seus formadores como uma oportunidade para promover a necessária ligação entre a universidade e escolas de ensino médio e fundamental. Assim, os professores vivenciaram a possibilidade de refletir sobre sua prática, descobrindo formas de investigá-la sistematicamente, uma vez que conhecem seu contexto melhor do que qualquer outra pessoa.

Na Universidade Federal de Minas Gerais (UFMG), desde o ano de 2002, há um Projeto de EC de Línguas Estrangeiras (EDUCONLE), coordenado pela Professora Doutora Deise Prina Dutra. O EDUCONLE recebe professores de inglês das redes públicas, e eles participam de módulos teóricos e práticos e do curso de língua inglesa no Centro de Extensão da Faculdade de Letras (CENEX).

Dentro dos módulos da EC, encontra-se a pesquisa-ação que, em nosso entendimento, é um dos pontos de maior relevância no projeto, dada a sua peculiar característica de instigar o professor a pesquisar e (re)descobrir sua própria prática pedagógica.

Resumidamente, definimos o termo pesquisa-ação como a busca de uma compreensão mais elaborada sobre a prática do professor e / ou de solução de problemas previamente identificados. A pesquisa-ação é conduzida por professores que desejam promover algo para aprimorar sua prática.

Nunan (1992, p. 18) define pesquisa-ação como um estudo de caso escolar, feito por professores que se valem do status de participantes para desenvolver habilidades de observação, identificação de um problema real na sala de aula, ação e análise da prática docente. André (2004), discute a pesquisa-ação como aquela que envolve um plano de ação baseado em objetivos; um processo de acompanhamento e controle da ação planejada; e um relato de todo o processo.

A pesquisa-ação dentro do projeto EDUCONLE é de caráter colaborativo (SAGOR, 1993), uma vez que um grupo de professores com interesses comuns trabalham juntos em uma dada investigação, assistidos por um orientador / colaborador.

Este artigo se ocupa da análise dos deslocamentos identitários (re)velados ao longo de uma pesquisa-ação desenvolvida durante o ano de 2008, no EDUCONLE. O presente trabalho tece a perspectiva dos participantes envolvidos nessa experiência de reinventar os limites entre teoria e prática, universidade e escola, a partir de um projeto de pesquisa-ação.

\footnotetext{
${ }^{2}$ Referimo-nos, por exemplo, ao Núcleo de Assessoria Pedagógica NAP /UEL (GIMENEZ, 1999); ao Projeto de Educação Continuada PUC-SP (CELANI, 2002); ao Projeto de Educação Continuada de Viçosa (PECPLI-UFV) (BARCELOS; COELHO, 2005) e o Projeto EDUCONLE (UFMG), que apresentaremos a seguir.
} 
No período em que ocorreu a observação, o grupo em questão recebeu a colaboração de uma aluna do curso de doutorado em Linguística Aplicada da instituição, que acompanhou todos os passos da pesquisa realizada na sala de aula desses professores participantes.

Dessa forma, objetivamos discutir as representações que nos indicam como a identidade de cada uma das professoras, impulsionadas pela pesquisa, é (re)velada ao longo de toda ação e reflexão durante o período de observação. Assim, nossa discussão será constituída com base na escrita desenvolvida pelas professoras no decorrer de todo o projeto. $\mathrm{O}$ foco será mantido nas professoras, principalmente no que diz respeito ao modo com que elas se posicionam sobre sua prática, na escrita de seus diários. Portanto, não é nossa intenção analisar as atividades praticadas durante a pesquisa nem os resultados diretos na aprendizagem dos alunos.

A seguir apresentamos alguns termos que constituem nossa proposta de análise.

\section{2. (RE)VELANDO AS IDENTIDADES, IDENTIFICANDO-SE}

Não sei quantas almas tenho.

Cada momento mudei.

Continuamente me estranho.

Nunca me vi nem acabei.

Fernando Pessoa

Contrariando a formação de origem latina do termo identidade, na qual temos "idem" designando "o mesmo" e o sufixo "dade" como um estado ou qualidade, o trecho do poema de Fernando Pessoa, que abre a presente seção, transporta-nos a uma reflexão pela qual compreendemos identidade como algo sempre em constituição, em contínuo (inacabado) "estranhamento".

Etimologicamente, o conceito de identidade é tido como qualidade de algo que lhe é idêntico, imutável, permanente. No campo filosófico, sobretudo a partir de Aristóteles, Sócrates e Platão, esse termo foi usado para definir uma busca rigorosa da verdade das coisas, descobrindo aquilo que é da essência de cada objeto ou de cada ser. No entanto, a "crise de identidade" 3 ", instaurada, segundo Hall (1997), no final do século XX, fez com que novas identidades fossem exploradas, consequentemente, fragmentando o homem moderno, que antes era visto como sujeito unificado.

É desse modo que a noção filosófica de identidade é revisitada e reestruturada. Maher (1998), percebe o conceito de identidade como algo construído sócio-historicamente, um fenômeno essencialmente político, ideológico e em movimento constante. Também, considerando a importância social para a constituição da identidade, Norton (2000), defende que o termo está relacionado ao modo como a pessoa compreende sua relação com o mundo e como tal relação é construída através do tempo e do espaço. Dessa forma, o desenvolvimento da identidade só pode ocorrer a partir de uma relação intersubjetiva, na

${ }^{3}$ Segundo Hall (1997), essa crise refere-se a um processo mais amplo de deslocamento, e até mesmo à fragmentação do indivíduo moderno. 
qual o homem, em contato com o seu semelhante, está, inevitavelmente, inserido em um processo contínuo de reconhecer a si mesmo como uma pessoa, sendo, ao mesmo tempo, reconhecido como tal em um dado contexto (GEE, 2001).

Volkmann e Anderson (1998), pontuam que a discussão acerca da formação da identidade do professor deve ser vista como relevante no contexto educacional, para nos aproximarmos do apoio que alunos e professores realmente necessitam. Beijaard et al. (2004), assinalam que tal discussão também contribui para nosso entendimento e reconhecimento do que significa ser professor, nos dias atuais, nos ambientes escolares em constantes mudanças.

O significado de ser professor, um dos tópicos de nossa análise, pode ser discutido, ao apreendermos as representações desse professor acerca de seu ser (sua identidade) e fazer (sua prática). Para Coracini (2003a, p. 219), "toda representação se constrói a partir das experiências pessoais, mas não apenas: elas se constroem a partir das experiências dos outros, daqueles que nos cercam e que nos levam a crer nisto ou naquilo, que nos dizem quem somos". Assim, entendemos por "representações"

a relação do sujeito com os acontecimentos à sua volta, incluindo suas experiências, os outros sujeitos com os quais ele se relaciona e o modo como ele se vê e se posiciona a partir do olhar do outro. Nesse sentido (...) as tomadas de posição do sujeito se dão a partir de momentos de identificação nos quais o sujeito se reconhece e, inconscientemente, assume esses elementos como constituintes de suas representações, logo, de seu dizer e agir (REIS, 2006a, p. 4).

Segundo Grigoletto, 2003, as representações são constituídas pelos sujeitos, deixando escapar aspectos que revelam suas identidades e identificações. Nesse sentido, percebemos que as representações são decorrentes das imagens delimitadas pelos / nos sujeitos, constituindo sua subjetividade, uma vez que fazem parte do seu inconsciente e do modo como identidade e identificação são movimentadas (GHIRALDELO, 2006).

Defendemos aqui que a identidade dos professores está intrinsecamente ligada às suas histórias de vida, sobretudo à sua vida escolar, sendo movimentada a partir dos momentos de identificação insurgidos. De modo mais específico, defendemos que as relações delimitadas dentro de uma pesquisa-ação também representam uma possibilidade para que o fazer desses professores seja (re)significado a partir de inúmeros momentos de identificação.

No Dicionário de Psicanálise de Roudinesco e Plon (1998 [1944], p. 363), o termo identificação é resumido como "o processo central pelo qual o sujeito se constitui e se transforma, assimilando ou se apropriando, em momentos-chave de sua evolução, dos aspectos, atributos ou traços dos seres humanos que o cercam". Portanto, a relação é a condição primeira para que haja a identificação. Esta, por sua vez, faz com que o sujeito, além de se constituir, se (re)invente por meio do contato com o outro.

O conceito de identificação aparece ao longo da obra de Freud, particularmente na obra "A Psicologia de Grupo e a Análise do Ego" (1921). ${ }^{4}$ O autor inicia o capítulo intitulado Identificação definindo que esta "é conhecida pela psicanálise como a mais remota expressão de um laço emocional com outra pessoa”. Esse laço, ainda nos termos

${ }^{4}$ Trata-se de uma versão eletrônica, por isso omitimos o número da página. Ver listagem de referências. 
do autor, é ambivalente, uma vez que pode se tornar "expressão de ternura com tanta facilidade quanto um desejo do afastamento de alguém".

A identificação, portanto, é um elemento chave para o funcionamento e sucesso das investidas do grupo de pesquisa-ação, uma vez que é isso que estabelecerá se haverá ou não o laço responsável por fazer com que o grupo se mobilize, trabalhe. É importante compreender aqui o lugar do orientador na constituição desse laço, haja vista a projeção que lhe é dirigida (pelo professor) desde o primeiro encontro.

Quando chega a um curso de EC, o professor, de um modo geral, anseia por respostas para as suas questões e por solução para suas frustrações, companhia para o seu fazer, muitas vezes solitário. O professor busca um curso de EC movido pelo desejo de apreender uma teoria para suprir as lacunas de sua prática, ou mesmo pela necessidade de compreender a prática que desenvolve por meio de alguma teoria. Não raras vezes, essa expectativa do professor (na posição de aluno na EC) é direcionada ao formadororientador, tomado como seu ideal.

Caberá ao formador-orientador, portanto, estimular o professor-aluno a uma responsabilização, ${ }^{5}$ para que ele investigue suas próprias questões. Assim a tarefa do orientador é permitir e alimentar que a diferença de cada um se faça respeitada no grupo. Longe de qualquer receita, é por meio do uso da linguagem, mais especificamente da fala e da escuta do que o professor tem a dizer, ancorado pelo conhecimento teóricometodológico, que esse trabalho pode fazer com que a prática pedagógica dos professores na EC seja transformada.

Ao procurar um curso de EC, o professor busca construir uma identidade profissional que represente outra possibilidade de ensinar. Nesse contexto, a pesquisa lhe é apresentada e, com ela, a necessidade de reorganizar, (re)avaliar e reinventar saberes que compõem a prática pedagógica. A figura do orientador-formador poderá ser a ponte que possibilitará ao professor (re)significar seu fazer, com base nos questionamentos acerca daquilo que busca. Cabe, nesse processo, identificar seu problema, por meio de uma reflexão sobre seu contexto e os sujeitos envolvidos na ação de ensinar / aprender; desenvolver e implementar um plano de ação para solucionar o problema percebido; observar os efeitos dessa ação na sala de aula; e, por fim, refletir e avaliar o efeito das ações em seu ambiente escolar. Resumidamente, trata-se de um movimento dinâmico de teorização (sistematização) daquilo que os professores vivenciam em suas salas de aula e, ao mesmo tempo, um espaço para se colocar em prática toda a teoria descoberta no projeto. A FIG. 1 apresenta a dinâmica desse processo.

${ }^{5}$ Segundo Reis (2010, p. 804), o termo "responsabilização" refere-se ao "ato de se assumir, ou assumir sua condição, procurando compreender sua ação, sucessos e frustrações a despeito de todas as adversidades que "conspiram" contra tal ação". 


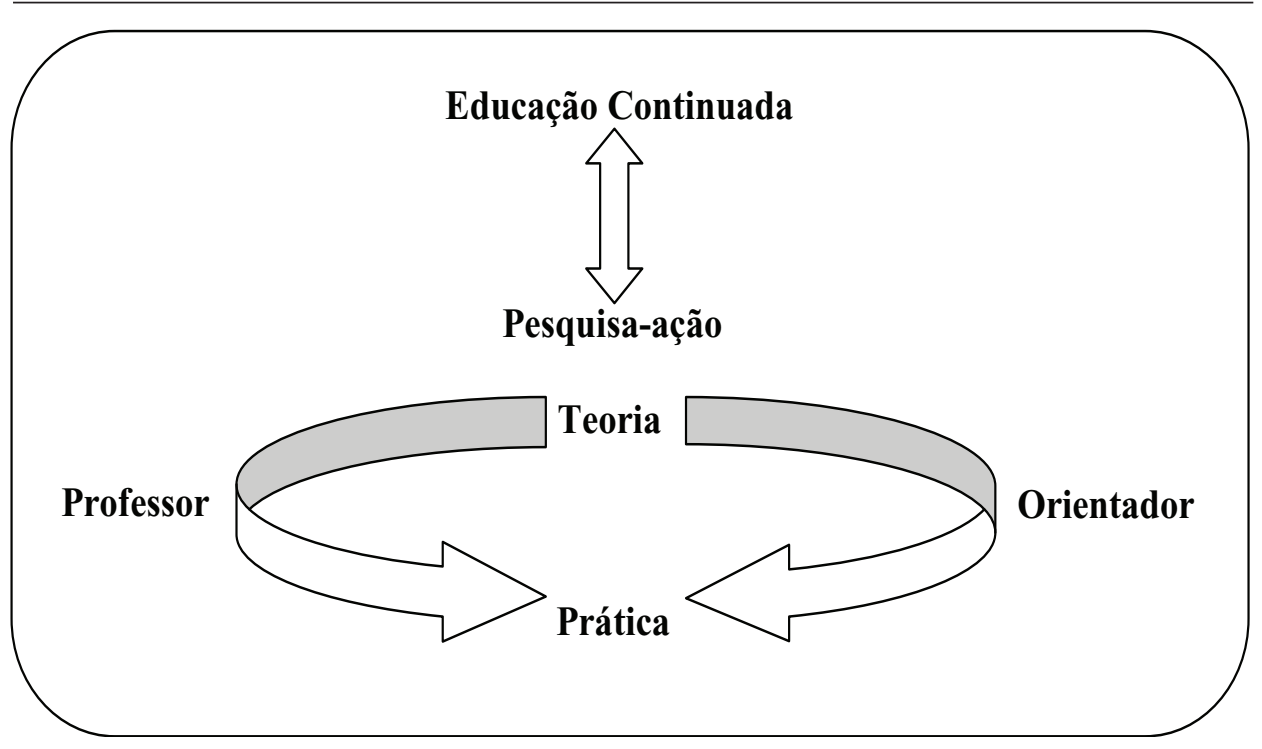

Figura 1 - Teorizando a Prática ou Praticando a Teoria?

Esse movimento, impulsionado pela / na pesquisa do professor-aluno, faz com que este trabalhe a articulação entre teoria e prática, constituindo um fazer mais responsável ao se implicar em todas as realidades de sua sala de aula, bem como nas possibilidades de transformação.

A partir da experiência motivadora do presente trabalho, asseveramos que os deslocamentos identitários, motivados pelo processo de pesquisa-ação, afetam não apenas a prática pedagógica, mas, principalmente, o modo com que ela constitui e afeta a subjetividade das professoras envolvidas.

A escrita desenvolvida pelas professoras no período de pesquisa, mais que um registro, revelou-se como um espaço no qual sua subjetividade era deslocada, reorganizada e, posteriormente, apreendida por meio das análises. Para Foucault (1992 [1983]), o processo de escrita, troca e reflexão acerca das experiências desempenha um papel essencial no modo como a subjetividade de cada um é constituída.

Na seção que se segue, daremos informações sobre o contexto e sobre as participantes desta pesquisa.

\section{CONTEXTO E PARTICIPANTES}

Este artigo investiga alguns momentos da trajetória de pesquisa de duas professoras da rede pública de ensino de Minas Gerais, orientadas por uma aluna do curso de doutorado em Linguística Aplicada da Universidade Federal de Minas Gerais, com base na experiência em um curso de EC no ano de 2008. Uma delas é Ana Márcia, que é professora de inglês há dezessete anos e trabalha no Ensino Fundamental e Médio da 60 
Trab. Ling. Aplic., Campinas, 50(1), Jan./Jun. 2011

rede municipal de ensino da cidade de Contagem - MG. A outra é Lucienne, que também é professora de inglês há onze anos e trabalha na rede estadual de ensino na cidade de Timóteo - MG.

Ao longo do ano de 2008, as professoras se reuniram, sistematicamente, (semanalmente ou quinzenalmente) com a orientadora, para que toda a ação fosse determinada, seus resultados avaliados e as ações futuras delineadas. Houve também reuniões virtuais, por meio de inúmeras mensagens de correios eletrônicos, trocados durante o período, além da escrita de diários, detalhada na seção que se segue.

\section{METODOLOGIA: CONSTITUIÇÃO DO CORPUS E MARCAS DISCURSIVAS}

A presente análise seguirá o dispositivo de escuta discursiva (ORLANDI, 1999), por meio do qual são evidenciados os gestos de interpretação que se ligam aos processos de identificação constituídos nas relações entre os sujeitos, assim como nas filiações de sentidos nos quais os dizeres são formulados. Procuramos, por meio dessa escuta, descrever a relação do sujeito com sua história, estabelecendo uma relação entre descrição e interpretação e, assim, investigando as representações que constituem as identidades dos sujeitos inseridos no projeto de EC.

Ao longo da pesquisa, cada professora escreveu seu diário, no qual eram apresentadas reflexões sobre seu cotidiano escolar e sua trajetória de pesquisa. Serão analisados dezoito (18) excertos desses diários, apresentados em inglês ou em português, considerando a escrita original das professoras. Também analisamos as respostas dadas pelas duas professoras a um questionário ao final da pesquisa-ação. ${ }^{6}$

Uma vez que nosso trabalho de escuta discursiva consiste em apreender traços da subjetividade das professoras e os momentos de deslocamentos, procuramos ler com o escrito (LACAN, 2007 [1975-1976]). Isso significa que aquilo que aparece escrito é o ponto de partida, bem como a referência sobre a qual nosso olhar estará voltado. É desse modo que procuramos relacionar o escrito com o próprio escrito, vendo nos fios dessa tessitura o modo com que o sujeito dessa prática é constituído, considerando que uma escrita é "um fazer que dá suporte ao pensamento" (LACAN, 2007 [1975-1976], p. 140).

Nosso corpus será analisado com base nas ressonâncias discursivas de SerraniInfante (2001), que define que há ressonância quando certas marcas linguístico-discursivas se repetem, tendendo a construir um significado predominante: as representações. Logo, a análise será pautada no conteúdo dos enunciados e nos modos de enunciar que os constituem. Em outras palavras, investigamos o modo como os efeitos de sentido são produzidos, mobilizados e como ressoam para a constituição identitária do professor em

\footnotetext{
${ }^{6}$ Professores e orientadores do projeto responderam a questionários para o estudo intitulado "O professor (de LE) e o formador em (um) projeto de EC: as (in)certezas dessa / nessa relação" (cf. REIS, 2010). Questões: 1) Como você enxerga o professor que a orientou na pesquisa-ação? 2) A partir do primeiro contato, quais foram as suas expectativas em relação a essa pessoa? 3) O que você recebeu, de fato? 4) Comente a ação dessa pessoa na pesquisa-ação? 5) Comente se e como o fazer dessa pessoa vai contribuir para a sua prática pedagógica. 6) Fale da presença dessa pessoa e da pesquisa-ação em relação ao que você vivenciou em todo o projeto de EC. 7) Fale dessa pessoa em relação àquilo que ficará ou não após o curso.
} 
uma pesquisa-ação. Assim, interessamo-nos por aquilo que é dito e / ou intencionado dizer; pela contradição e conflitos e os já-ditos (interdiscurso) que estão entrelaçados na materialidade daquilo que é dito, evidenciado no fio do discurso (intradiscurso).

Assim, o conjunto de categorias das ressonâncias discursivas é o seguinte (quatro categorias e três subcategorias): ${ }^{7}$

1. repetição de itens lexicais de uma mesma família de palavras;

2. repetição de itens de diferentes raízes lexicais, apresentados no discurso como semanticamente equivalentes;

3. repetição de construções que funcionam parafrasticamente;

4. modos de enunciar presentes no discurso:

4.1 modo determinado e modo indeterminado de enunciar;

4.2 modo de definir por negações ou afirmações modalizadas ou categóricas;

4.3 modo de acréscimos contingentes por meio de incisas e de glosas.

Nossa análise estará centrada nas representações reveladoras das identidades das professoras quanto ao significado de ser professora; quanto às expectativas e projeções dentro do projeto / pesquisa e quanto à relação do professor-aluno com a orientadora.

\section{ANÁLISE E DISCUSSÃo DOS DADOS}

Compreendemos que atender a um projeto de EC é uma prática social capaz de fazer com que a identidade do professor seja desestabilizada e reorganizada. Esse processo não é instantâneo, nem mesmo está isento de angústias, conflitos, enfim, não há garantia de sucesso. Sabemos, no entanto, que o professor precisará estar disposto a executar um intenso trabalho consigo e com os acontecimentos à sua volta para que suas representações sejam mobilizadas.

A seguir discutiremos esse primeiro momento de trabalho no qual o professor volta seu olhar para si e para o seu fazer.

\section{CADA MOMENTO MUDEI: MUITO PRAZER! SOU PROFESSORA.}

O olhar para si, localizando e pontuando aquilo que fazemos e acreditamos ser, requer uma responsabilização pela qual nos autorizamos a falar em primeira pessoa (REVUZ, 1998). Segundo a autora,

${ }^{7}$ Serrani-Infante (2001, p. 40) propõe apenas três categorias das repetições, a saber, a) itens lexicais de uma mesma família de palavras ou itens de diferentes raízes lexicais apresentados no discurso como semanticamente equivalentes; b) construções que funcionam parafrasticamente; c) modos de enunciar presentes no discurso (tais como o modo determinado e o modo indeterminado de enunciar; o modo de definir por negações, ou por afirmações modalizadas ou categóricas, modo de acréscimos contingentes através das incisas, glosas etc.). Porém, a partir de Reis (2006b; 2007) utilizamos uma subcategorização, no intuito de facilitar a operacionalização de suas categorias. 
o exercício requerido pela aprendizagem de uma língua estrangeira se revela tão delicado porque, ao solicitar, a um tempo, nossa relação com o saber, nossa relação com o corpo e nossa relação com nós mesmos enquanto sujeito-que-se-autoriza-a-falar-em-primeira-pessoa, solicitam-se as bases mesmas de nossa estruturação psíquica, e com elas aquilo que é, a um mesmo tempo, o instrumento e a matéria dessa estruturação: a linguagem (...).

Revuz (1998), refere-se à aprendizagem de uma LE, mas acreditamos que, do mesmo modo que a aprendizagem de uma língua requer uma reorganização do sujeito em relação àquilo que ele apre(e)nde, a inserção em um projeto de $\mathrm{EC} /$ pesquisa-ação requer um investimento que exige que o professor se lance em um contínuo trabalho de reorganização de suas representações. O sujeito-professor passa a experimentar uma reflexão e relação com os saberes circulantes em sua (nova) realidade, com todos os outros envolvidos no projeto (e seus alunos também) e, sobretudo, uma relação consigo mesmo, a partir da qual ele vivencia o embate com o seu (velho) fazer, logo, com suas representações e com todas as angústias oriundas desse embate.

Assim, é por meio da linguagem que o professor se localiza no tempo e no espaço. É por meio da fala e / ou da escrita que o professor localiza aquilo que faz e aquilo que pode fazer em sua vida profissional, (re)organizando sua identidade a partir das novas experiências. Vejamos a seguir alguns dos excertos referidos: ${ }^{8}$

\section{[1]}

To be a teacher isn't an easy job. We have many things to do... but it's ok! (Ana Márcia)

[2]

I like being a teacher. I know... there are many problems in our classrooms since material things until students who don’t want to learn! (Ana Márcia)

\section{[3]}

A maior frustração de um professor é preparar uma aula e não conseguir plateia. Com turmas grandes (...) é muito frustrante porque tem aqueles que te ignoram, aqueles que não querem estudar e aqueles que querem uma boa aula e aqueles que angustiados como o professor, esperam a atenção da turma. (Lucienne)

\section{[4]}

Sempre reclamo da turma agitada, do pouco espaço na sala, da conversa paralela, mas agindo com mais atenção em minha ação vejo que estou pouco atenta para o que eu posso fazer para mudar esse jogo, ou melhor, esta aula. Será que minhas aulas despertam atenção daqueles que me ignoram? (...) (Lucienne)

\footnotetext{
${ }^{8}$ Ressaltamos que a data em que os excertos foram escritos foi omitida por dois motivos: primeiro porque uma das professoras não datava suas escritas; e, segundo, porque nosso objetivo não está centrado no estudo dos deslocamentos identitários por meio de um estudo cronológico, mas, antes, por conta dos sentidos mobilizados pelas participantes diante de sua experiência com a pesquisa-ação.
} 
Um sentido predominante na escrita das professoras Ana Márcia e Lucienne - que também faz parte de um discurso corrente - é que o exercício da profissão não é fácil. No excerto [1], por exemplo, por meio do modo de enunciar por uma negação categórica, a professora afirma que "to be a teacher isn't an easy job". Há no corpus a repetição do item lexical "é difícil", ou outras palavras que parafrasticamente significam essa dificuldade, por exemplo, a construção: "não é fácil". Enfatizamos, no entanto, que, no decorrer do processo de pesquisa-ação registrado no diário, as professoras foram descobrindo uma forma de se responsabilizar por tais dificuldades e / ou problemas.

Percebemos que a dificuldade (paralisante) de ser professor(a) foi sendo substituída por uma tentativa constante de superação. Essa superação foi sempre introduzida por um posicionamento: "I like being a teacher", e, sobretudo, por um questionamento feito pelo próprio professor e / ou pelo grupo de pesquisa-ação durante as reuniões. Observando o excerto [4], após delinear uma série de dificuldades da profissão, como "turma agitada, do pouco espaço na sala, da conversa paralela", Lucienne conclui sua escrita se autorizando a olhar para a sua relação consigo mesma e com o seu fazer - usando a primeira pessoa do discurso - e, responsabilizando-se, questiona: "será que minhas aulas despertam atenção daqueles que me ignoram?".

Um ponto relevante de tal tomada de posição é que a professora, ao se responsabilizar por aquilo que não dá certo em sua prática, poderá procurar formas de sair de tal desconforto, apesar de todas as dificuldades que fazem parte do cotidiano do professor, como turmas cheias, falta de recursos etc.

Também faz parte do discurso corrente que ao professor é atribuído um acúmulo de tarefas. Os dizeres que constituem esse sentido predominante circulam historicamente e seguem produzindo efeitos de sentido. Notemos o modo determinado de enunciar de Ana Márcia no excerto [1]. A professora inicia sua fala afirmando que "ser professora não é um trabalho fácil" e prossegue enunciando na primeira pessoa do plural (nós): "we have many things to do". Para Benveniste (1966), o uso do pronome nós é um eu ampliado que possibilita que o locutor integre ao seu dizer outros locutores. Ao enunciar na primeira pessoa do singular Ana Márcia se inclui, mas também fala por uma classe, um pensamento comum, o que dá mais força e confere um estatuto de verdade ao seu dizer.

Ao contrário disso, Lucienne, no excerto [3], por meio do modo indeterminado de enunciar, distancia-se daquilo que é dito com a seguinte construção linguística: "a maior frustração de um professor”. A presença da preposição de, seguida do artigo indefinido $u m$, faz com que a frase seja representante da verdade de uma classe ("de um professor"), sem que o enunciador seja, necessariamente, incluído. Este prossegue se distanciando: "te ignoram" no lugar de me ignoram e "angustiados como o professor", no lugar de angustiados como eu. É assim que definimos que enunciar em primeira pessoa requer trabalho e responsabilização sobre aquilo que enunciamos. No excerto seguinte, percebemos que Lucienne assume tal posição ao fazer o questionamento, já discutido acima, em primeira pessoa: "será que minhas aulas despertam atenção daqueles que me ignoram?".

Os excertos ainda apresentam ocorrências discursivas que merecem uma breve discussão, por reafirmar que a nossa constituição identitária se revela múltipla e em construção contínua e que podemos depreender essa afirmação por meio de nossas 
representações que denotam o modo como nossa identidade está tecida. Voltemos, então, aos excertos [3] e [4], destacando os seguintes trechos: "A maior frustração de um professor é preparar uma aula e não conseguir plateia" e, "vejo que estou pouco atenta para o que eu posso fazer para mudar esse jogo". Sabemos que uma sala de aula é composta por professor e alunos com lugar e posição historicamente delimitados. Falando do lugar e posição de um (professor) e do outro (alunos), fica, no mínimo, conflitante, pensarmos nesse ambiente como um palco / show, no qual o professor atua e o aluno é a sua plateia.

No entanto, consideramos as contradições e conflitos que nos constituem e percebemos que, por causa dos sentidos sócio-históricamente circulantes, a sala de aula pode, sim, ganhar conotação de um grande palco, de um lugar onde o professor atua ativamente e ao aluno é conferido apenas o papel passivo de plateia. Esse tipo de representação, silenciosamente, constitui ainda o fazer de muitos professores nos dias atuais, construindo e alimentando um cenário infrutífero para que a aprendizagem ganhe forma. Assim, por meio do escorregão (lapso) na fala de Lucienne, depreendemos sua representação acerca de seus alunos (mera plateia), e vislumbramos o modo como sua identidade (ou momento de identificação) é (re)velada.

A responsabilização chega até o fazer do professor, possibilitando que este se enxergue e todo o contexto do qual ele faz parte. O palco precisa ser desarmado e professores e alunos precisam atuar (ativamente) no ensino e na aprendizagem. Observamos um deslocamento nesse sentido, por meio da seguinte construção: "o que eu posso fazer para mudar esse jogo, ou melhor, esta aula". A professora afirma que precisa mudar "esse jogo", mas por meio da glosa9: "ou melhor", ela redireciona seu dizer, enxergando sua (sala de) aula. Mais que um jogo em que um dos lados sempre ganha e o outro, necessariamente, perde, a aula é composta por pessoas que precisam alcançar seus objetivos. A reformulação na fala de Lucienne nos permite entender uma nova forma de enxergar e analisar seu contexto de atuação profissional, posicionando-se em seu fazer.

Vejamos os seguintes excertos:

\section{$[5]$}

Since I have decided to return to school, I always ask myself if it's fair to my family (because all my spare time I'm working) but when I read the students' sentence, I know that what I'm doing is right. Although teachers' working conditions must be changed. (Ana Márcia).

\section{[6]}

I'm tired... but I can't give up. Sometimes I ask some questions to myself. Am I doing the right things?

I was very (upset) with my grade on the test. I had a bad grade. Was it my fault? What am I doing? What am I learning? Am I not good enough? I'm sad ... sad... será que vale a pena??? (Lucienne).

\footnotetext{
${ }^{9}$ Ligada à atividade de reformulação, a glosa se apresenta como uma explicação, comentário, desconstrução e esclarecimento do que foi dito anteriormente (SERRANI, 1993, p.45).
} 
[7]

Estou cansada... A lembrança das carinhas de meus alunos me dá uma injeção de animo, é verdade, lembrar dos olhares das pessoas nos faz perceber e querer muitas coisas. Eles precisam de mim e eu preciso deles. (Lucienne).

Observe-se nesses excertos o contínuo estranhamento vivenciado por um professor em pesquisa-ação, ao ter de reorganizar suas representações em meio a tantas demandas e embates. Os conflitos surgem e com eles a angústia que pode impulsionar ou fazer com que o professor recue. Nos diários das professoras é recorrente a construção parafrástica, cujo sentido aponta para o questionamento se elas estavam fazendo o que era certo para suas vidas, devido às exigências do projeto (suas leituras, aulas, reuniões, planejamentos etc.): "I always ask myself if it's fair to my family" e "sometimes I ask some questions to myself. Am I doing the right things?". É importante salientarmos como os momentos de identificação capturam as professoras, fazendo com que elas transitem entre os lugares de professora, aluna, mãe e é assim que as representações são reorganizadas. Percebemos que suas questões familiares, denotadas em "if it's fair to my family", se contrapõem às de aluna: "(...) to return to school" / "(...) with my grade on the test (...) What am I learning?" e as professoras explicitam suas inquietações, acalmadas por meio das mudanças em seu fazer.

Observamos, por exemplo, que, no excerto [7], Ana Márcia muda o curso de seu dizer por meio da incisa adversativa mas ("but"), reafirmando, ao verificar os resultados da produção de seus alunos a partir de seu novo fazer, que está fazendo a coisa certa: "but when I read the students' sentence, I know that what I'm doing is right". Do mesmo modo, a indagação 'se a experiência vale todo investimento e cansaço', encontra alento no resultado dos alunos depois do novo fazer de Lucienne: "a lembrança das carinhas de meus alunos, me dá uma injeção de animo". A glosa, explicativa e enfática, "é verdade", nos mostra a reflexão da professora acerca do olhar do outro que está sempre a nos constituir: "lembrar dos olhares das pessoas nos faz perceber e querer muitas coisas".

Um item lexical que continuamente se repete é a palavra cansada / tired. Outro item recorrente é o vocábulo medo. Segundo Coracini (2003b, p. 149), no ensino-aprendizagem, o medo pode representar "o medo do estranho, do desconhecido, o medo do deslocamento ou das mudanças que poderão advir". Observemos esses excertos:

[8]

O questionário ficou pronto para aplicarmos nas turmas numerosas. De repente me deu um medo de querer que tudo dê certo e isso falhar... mas precisamos tentar, percebo que os meninos já não aguentam mais estudar do jeito que estão. A sala de aula, às vezes, parece uma feira lotada, dispersa. Quero muito que dê certo. Minha cabeça fervilha, preciso mudar minhas aulas (Lucienne).

\section{[9]}

We are all involved in doing our community works and my students entered in it but they are not writing their profiles... I don't know but in my opinion, they are afraid of writing in English. And I have to confess that I'm afraid too... I'm not an expert in technology... so we are all afraid... but we can deal with our fear (Ana Márcia). 
Por meio dos excertos [8] e [9], podemos apontar dois momentos distintos da pesquisa-ação: o primeiro, cuja ação principal do grupo foi a elaboração e aplicação de um questionário para os alunos e, o segundo, a criação de uma comunidade virtual no Orkut $^{10}$ foi a grande ação.

Podemos perceber nos excertos que o medo surge a partir do enfrentamento com o novo e com todas as possíveis mudanças daí resultantes: “(...) in my opinion, they are afraid of writing in English. And I have to confess that I'm afraid too (...)". Não somente o enfrentamento com o novo, o medo também surge por causa do desejo de controlar todos os possíveis furos. Desse modo, há o desejo (da ilusão) de controle para garantir que tudo dê certo: “(...) me deu um medo de querer que tudo dê certo e isso falhar...".

Discutimos, acima, a forma como a identidade das professoras inseridas em um projeto de EC é revelada e recriada ao longo dessa experiência com o contato com o outro e, sobretudo, do enfrentamento daquilo que as constitui (suas limitações, medos, demandas, questionamentos etc.). Percebemos, com isso, que a participação do professor em uma pesquisa-ação pode significar um delicado (não isento de conflitos, nem de contradições) trabalho de (re)significação de sua prática, permitindo que muitas de suas representações caiam por terra ou morram, como afirma Lucienne:

[10]

Estou vivendo dois momentos em minha vida. É como se uma parte de mim estivesse morrendo. De repente, um monte de coisas que acreditava morreram. Mas, entrar na sala de aula e conversar com os meninos sobre a comunidade, faz nascer em mim uma esperança e uma certeza de que trilhei (trilhamos) o caminho certo. Valeu! (Lucienne).

O excerto acima explicita a complexidade de sensações, sentimentos e angústias que fazem parte desse processo de reconstituição identitária. $\mathrm{O}$ alento de tal angústia é, novamente, a constatação de que as mudanças são favoráveis ao ensino-aprendizagem de LE: "faz nascer em mim uma esperança e uma certeza de que trilhei (trilhamos) o caminho certo". Salientamos, por fim, a glosa explicativa introduzida por meio do verbo trilhamos, entre parênteses, apresentado pela professora. Após destacar que acredita ter trilhado o caminho certo conjugando o verbo trilhar na primeira pessoa do singular ("trilhei"), Lucienne acrescenta que houve a companhia do grupo de pesquisa-ação e, sobretudo, de seus alunos: "mas ao entrar na sala de aula e conversar com os meninos sobre a comunidade...", que, nessa circunstância, abandonam a posição de plateia para se tornarem sujeitos na empreitada descrita (trilhamos).

Concluímos, assim, essa subseção em que apresentamos o professor, suas mudanças e rearranjos identitários e, mais que isso, seu prazer em assumir uma posição de responsabilização, por meio da qual o sujeito se autoriza a enunciar em primeira pessoa: I like being a teacher!

${ }^{10}$ Professoras, alunos e a colaboradora participavam dessa comunidade, mas não nos ateremos na descrição dessa ação e seus resultados no presente trabalho. 
REIS, SILVA e TORRES - Teorizando a prática ou praticando a teoria...

\section{CONTINUAMENTE ME ESTRANHO: EXPECTATIVAS E RELAÇÕES}

Observemos os seguintes excertos:

\section{[11]}

I am doing Educonle because I want to improve myself and contribute to my students development. I have many doubts: if I can do all the things that we are asked to do... what can I do in order to improve my practice?(...) but I'm sure... I'll do my best! (Ana Márcia).

\section{[12]}

Fazer parte do Projeto de Educação fez meus olhos brilharem, não por ser uma luz no fim do túnel, mas por ser um processo parecido com a maiêutica de Sócrates conhecer-te a ti mesmo e dar luz ao conhecimento. Criticar minhas ações, analisar, repensar (...) (Lucienne).

Os excertos [11] e [12] nos permitem demarcar as projeções do professor em relação ao projeto de EC ressoantes na escrita. Assim, o desejo de se superar é sempre o fator decisivo para que o professor procure o projeto. Notemos que, no excerto [11], Ana Márcia cita seu desejo de superação, mas seu modo de definir pela afirmação categórica - "I want to improve myself" - nos mostra que a professora não limita tal desejo de melhora ao seu fazer pedagógico. Entendemos que, ao procurar formas de se desenvolver como pessoa, o professor estará se desenvolvendo também como profissional, uma vez que as diversas realidades vivenciadas pelo sujeito-professor sempre se entrelaçarão, fazendo com que ele continuamente se estranhe.

Em seguida, por meio da conjunção aditiva $e$ ("and"), a professora afirma fazer o curso também na tentativa de contribuir para o desenvolvimento de seus alunos ("contribute to my students development"), no entanto, isso vem em segundo plano, o que denota que há uma meta pessoal a ser cumprida em primeira instância. Note-se que Ana Márcia se questiona acerca de sua prática: "what can I do in order to improve my practice?". E, a nosso ver, esse questionamento será essencial para a busca de novas possibilidades, de novas metas.

O método maiêutico de Sócrates consiste exatamente em questionar(se), inquirir(se), perguntar(se). Esse método estabelece que o interlocutor seja provocado por meio de várias perguntas que o levem a descobrir seus conhecimentos e verdades próprias: conhece-te a ti mesmo, lema exaltado no excerto [12]. Obviamente sabemos que tal lema também transita na ordem das imagens, daquilo que acreditamos que somos. Há, no entanto, um ponto no qual não obteremos resposta, um ponto de obscuridade sob o qual reside um eterno desconhecimento acerca da origem daquilo que dizemos, ou fazemos; algo que, mesmo que não concordemos com a situação que se apresenta, estará sempre a nos surpreender com seu inadvertido retorno. De qualquer modo, o questionamento é sempre um meio de nos responsabilizamos por nossas tomadas de posição. Nos termos de Neves (2002, p. 257) "somos justamente empurrados a 'saber mais', a caminhar em alguma direção por essa 'inconsciência' do desejo". 
À luz discursiva, com a denegação (não), Lucienne afirma (e não nega) que sua participação no curso é "uma luz no fim do túnel": "não por ser uma luz no fim do túnel". Nesse sentido, a conjunção adversativa mas funciona como glosa, pois acrescenta uma explicação que esclarece o que foi dito, cujo núcleo é justamente a palavra luz: "mas por ser um processo parecido com a maiêutica de Sócrates conhecer-te a ti mesmo e dar luz ["no fim do túnel"] ao conhecimento". Interessante também é a escolha lexical da expressão fazer parte, cujo sentido predominante carrega uma postura ativa por parte do enunciador, uma reafirmação de pertencimento, um rastro de um deslocamento identitário.

Um ponto chave dos movimentos identitários das professoras envolvidas nessa pesquisa-ação é a relação entre os envolvidos. Logo, defendemos que a relação entre formador e professor em EC pode delimitar o sucesso ou o insucesso de toda a pesquisa a ser desenvolvida pelo grupo (REIS, 2010). Observemos as respostas dadas aos questionários, compiladas ${ }^{11}$ a seguir:

\section{[13]}

Acho que nosso grupo foi premiado com essa orientadora porque ela se interessa por nossas vidas (medos, dificuldades, problemas, alegrias e tristezas). Ela sempre se apresentou, agiu e foi muito mais que uma orientadora, ela é parte do nosso grupo... Não caminhou à nossa frente, mas ao nosso lado, o tempo todo. Ela nos questiona, incentiva, alerta, direciona, ouve. (...) Sempre penso nela na hora de planejar: o quê, para quem, por quê, com que finalidade, é de fato, o lesson planning. Através das leituras sugeridas, dos encontros e conversas, ela, gradual e amigavelmente, nos fazia refletir sobre nossos fracassos, sucessos, medos e interesses. Ela sempre está presente, disponível e disposta. Ficará o cuidado com o planejamento, o ouvir o outro, ouvir a mim mesma. E o incentivo a continuar estudando para ensinar mais e melhor. (Ana Márcia)

\section{[14]}

O falar, o investigar constante para minha reflexão, o apoio teórico e o mais importante, o incentivo, sempre estava assistida, alguém caminhava comigo e me incentivava a dar o próximo passo. Me senti segura. A vontade de fazer parte do grupo, de andar juntas e o entusiasmo da professora (orientadora) em cada passo fez a diferença no nosso grupo. (...) Eu sentia o seu entusiasmo e a vontade que o grupo funcionasse unido e integrado. A todo instante, eu me senti segura e com vontade de fazer, aprender e acertar (...). Minha orientadora fez despertar em mim a minha reflexão. Muitas vezes eu realizava alguma coisa e não refletia sobre o resultado e o processo, o escrever, o analisar falas, atos e até o silêncio me fez rever minhas atitudes e prática pedagógica. Minha orientadora, durante todo o projeto, me despertou a um caminhar reflexivo e constante. Este despertar, uma provocação, para que minha reflexão não fosse interrompida, me ajudou a não abandonar meus objetivos. Em cada encontro, cada e-mail, fui impulsionada a querer mudar e acertar (...). (Lucienne)

\footnotetext{
${ }^{11}$ Agrupamos as respostas de cada professora. Veja as perguntas na nota número 5.
} 
Apesar de terem sido produzidos por enunciadoras diferentes, os excertos [13] e [14] apresentam itens lexicais que se repetem, constituindo alguns sentidos predominantes. Dentre eles, o sentido que aponta a presença do orientador como crucial para o desenvolvimento e sucesso da pesquisa-ação e, mais que isso, para a recriação do fazer das professoras: "ela nos questiona, incentiva, alerta, direciona, ouve. (...) Sempre penso nela na hora de planejar: o quê, para quem, por quê, com que finalidade, é de fato, o lesson planning". Desse modo, torna-se possível afirmarmos que ao orientador é conferida a tarefa de propiciar o "apoio teórico"; questionar, incomodar, retirar da zona de conforto que pouco faz com que o sujeito se mobilize; e, sobretudo, alimentar uma escuta entre os participantes do grupo: "através das leituras sugeridas, dos encontros e conversas (...) fazia refletir sobre nossos fracassos (...) o ouvir o outro, ouvir a mim mesma" / "o processo, o escrever o analisar falas, atos e até o silêncio, me fez rever minhas atitudes e prática pedagógica. (...) uma provocação".

O que ainda merece destaque nesses excertos é a possibilidade de vislumbramos uma parceria escola-universidade real e mobilizadora. Voltando ao excerto [11], Ana Márcia explicita sua preocupação sobre se conseguirá fazer tudo aquilo que é demandado: "if I can do all the things that we are asked to do". Observe-se também o seguinte excerto:

[15]

I have many doubts if I can do all the activities, but I'm sure that all they ask us to do is right, I mean, all activities have a purpose: show us how to work with our own students. (Ana Márcia)

Como apontado acima, há um sentido historicamente constituído de que a universidade - na pessoa de quem enuncia dessa posição - tem um saber legitimado e incontestável; tem as respostas e todas as receitas: "I'm sure that all they ask us to do is right (...) show us how to work with our own students". Esse sentido se revela perigoso se não for desestabilizado. Sabemos que nenhuma receita será capaz de transformar de modo significativo a prática do professor, uma vez que esta não será capaz de fazer com que as representações que constituem a identidade desse professor, sejam deslocadas. Também sabemos que à universidade pertencem muitas teorias, mas que de nada servirão se forem vistas como um meio fechado em si. À escola pertence a possibilidade de experiência e até formulação daquilo que realmente poderá transformar a prática.

Os excertos [13] e [14] nos apresentam a parceria escola-universidade, na qual não existe um detentor de uma "verdade irrevogável," mas um provocador atento às verdades trazidas (e escondidas) pelo próprio professor; alguém que caminhe com ele, interrogando-o e ouvindo-o, e não oferecendo respostas vagas ou fórmulas. Nas palavras de Ana Márcia, a orientação deve ser feita por uma pessoa que seja "parte do nosso grupo... Não caminhou à nossa frente, mas ao nosso lado, o tempo todo".

Vejamos, por fim, estes excertos:

[16]

(...) I want to write about our presentation today at Educonle, in my opinion it was great! (...) Thanks Action Research team! Thanks a lot! It was a great experience and I'm very happy. (Ana Márcia). 
[17]

The purpose of our (work) study was to investigate the problems concerning teaching in large classes. Now I believe that our study, reflection, make the difference in my teaching. All the class improved, I think that my class observation changes my teaching. The problem wasn't a large class, the problem was boring classes. (Lucienne).

[18]

I know that I'm too involved with my class, my students and they realized that. It's great to see how they are involved. Yes action research is the way! (Lucienne).

Para além de qualquer receita, o que atingiu e mobilizou a identidade dessas professoras foi o intenso processo de estudo, de investigação, de escuta, de escrita e de provocação durante o ano em que a pesquisa-ação ocorreu. Esse processo fez com que as professoras desenvolvessem sua observação e crítica em relação ao seu fazer, como vemos na afirmação categórica de Lucienne: "now I believe that our study, reflection, make the difference in my teaching. (...)".

As participantes desse processo de deslocamento identitário vivenciaram o elemento fundamental da pesquisa-ação: a ação colaborativa - "thanks Action Research team!". Defendemos, por fim, que, sem essa ação, os outros elementos - a saber: reflexão, teoria, atividades comunicativas etc. - perdem força e legitimidade.

Desse modo, concordamos que, continuamente se estranhando em uma pesquisaação, o professor nos revela sua constituição identitária, ao mesmo tempo em que suas representações se desestabilizam e são recriadas para uma prática mais efetiva: "Yes, action research is the way!".

\section{NUNCA ME VI NEM ACABEI}

Ao analisarmos os deslocamentos identitários das participantes desta pesquisa, percebemos que eles não se deram apenas por meio de uma demanda de reflexão, mas por uma série de identificações que garantiram o sucesso das investidas do grupo de pesquisaação. Ainda assim, concordamos com Hon (2009, p.156), que defende "um revezamento entre "velhas práticas" e a tentativa do "algo novo", porém não a completa troca de um pelo outro".

A interrogação apresentada no título do artigo - Teorizando a Prática ou Praticando a Teoria? - revela-se, finalmente, como o uso de uma marca discursiva que visa enfatizar que qualquer mudança na prática pedagógica será possível apenas ao entrelaçar teoria e prática, ao modo como o sujeito professor assume sua posição subjetiva e, a partir dela, constitui seu fazer, seu dizer e ser.

A escrita aqui delimitada, mais do que uma tentativa de entrelace das instâncias teóricas e práticas entre a academia e a escola, representa as posições subjetivas assumidas de forma "responsável" durante toda a experiência da pesquisa-ação, e posteriormente, a partir do desejo de falar sobre (si) ela. O desejo de deixar inscrito aquilo que deu certo, 
não com intuito de servir como um modelo para a elaboração de novas teorias, tampouco como uma receita para outros professores em desespero com a infertilidade de sua prática. Mas, sim, para promover a escuta do professor com tudo aquilo que ele tem a dizer sobre sua história, seu fazer, suas angústias e desafios e, consequentemente, seus deslocamentos identitários, enfrentados a partir de uma proposta de pesquisa de sua própria ação.

Defendemos, por fim, que jamais poderemos prever os rumos que a prática das professoras atuantes na pesquisa-ação seguirá após essa experiência. O que podemos afirmar é que, mesmo que haja uma tentativa (mesmo que inconsciente) de recuar, seu processo inacabado (nem acabei) não as reportará ao ponto exato do qual partiram no início da pesquisa. Desse processo de deslocamentos e de descobertas de identidade(s) ficarão as sementes que, silenciosa e continuamente, poderão ser germinadas. Não estamos e nem queremos estar prontos, acabados: muito melhor é que continuemos a nos estranhar.

\section{REFERÊNCIAS BIBLIOGRÁFICAS}

ANDRÉ, M. E. D. (2004). A Etnografia da prática escolar. ed. 11ª Campinas, SP: Papirus.

BARCELOS, A. M. F.; COELHO, H. S. H. PECPLI: (2005). Ecologia e ritmo de um projeto inicial de educação continuada. In: ANAIS DO ENCONTRO NACIONAL DE PROFESSORES UNIVERSITÁRIOS DE LÍNGUA INGLESA, 18, Fortaleza.

BEIJAARD, D. et al. (2004). Reconsidering research on teachers' professional identity. Teach. Educ., New York, v. 20, n. 2. p. 107-128.

BENVENISTE, E. (1966). Problemas de linguística geral. v. 1. Campinas, SP: Pontes.

CELANI, M. A. A. (2002). (org.) Professores e formadores em mudança. Campinas: Mercado de Letras.

CORACINI, M. J. (2003a). A celebração do outro. In. CORACINI, M. J. F (org.). Identidade e Discurso. Campinas: Argos Ed. Unicamp, p. 197-221.

.(2003b). Língua estrangeira e Língua materna: uma questão de sujeito e identidade. In. CORACINI, M.J.F (org). Identidade e Discurso. Campinas: Argos Ed. Unicamp, p. 139-159.

FOUCAULT, M. (1983). A escrita de si. In: O que é um autor? São Paulo: Vega Passagens. 1992.

FREUD, S. (1921). Psicologia de grupo e a análise do ego. In: Edição eletrônica brasileira das obras completas de Freud. Rio de Janeiro: Imago, v. 23. CD-ROM.

GEE, J. P. (2001). Identity as an analytic lens for research in education. In: SECADA, W. G. (ed.). Review of research in education. Washington, D.C.: American Educational Research Association. p. 99-125.

GHIRALDELO, C. M. (2006). Representações de línguas e formação de professores. In: CASTRO, S. T. R.; SILVA, E. R. (org.) Formação do profissional docente: contribuições de pesquisas em Lingüística Aplicada. Taubaté: UNITAU/Cabral/Livraria Universitária, p. 247-261.

GIMENEZ, T. (1999). (org.) Os sentidos do projeto NAP: ensino de línguas e formação continuada do professor. Londrina: Ed. UEL.

GRIGOLETTO, M. (2003). Representações, identidade e aprendizagem de língua estrangeira. In: CORACINI, M. J. F. Identidade e discurso. Campinas: Argos/Ed. Unicamp, p. 223-235. 
Trab. Ling. Aplic., Campinas, 50(1), Jan./Jun. 2011

HALL, S. (1997). A identidade em questão. In: A identidade cultural na pós-modernidade. Trad. Tomaz Tadeu da Silva, Guaracira Lopes Louro. Rio de Janeiro: Ed. DP\&A, p. 07-22.

HON, F. F. S. (2009). Deslocamentos identitários de professores no discurso sobre sua prática de avaliação no processo de educação continuada. 209. 177 f. Dissertação. (Mestrado em Linguística Aplicada ao Ensino de Línguas Estrangeiras) - Faculdade de Letras, Universidade Federal de Minas Gerais, Belo Horizonte.

LACAN, J. (1975-1976). O seminário, livro 23: O sintoma. Rio de Janeiro: Jorge Zahar, 2007.

MAHER, T. M. (1998). Sendo índio em português. In: SIGNORINI, I. (Org.) Língua(gem) e Identidade. Campinas: Mercado de Letras, p.115-138.

NEVES, M. S. (2002). Processo Discursivo e Subjetividade: Vozes Preponderantes na Avaliação da Oralidade em Língua Estrangeira no Ensino Universitário. 2002. 276 f. Tese (Doutorado em Linguística Aplicada) Instituto de Estudos da Linguagem, Universidade Estadual de Campinas. Campinas.

NORTON, B. (2000). Fact and fiction in language learning. In: Identity and language learning - Gender, ethnicity and educational change. Harlow, England: Longman/Pearson Education, p. 1-19.

NUNAN, D. (1992). Research Methods in Language Teaching. Cambridge: Cambridge University Press.

ORLANDI, E. P. (1999). Análise de Discurso: princípios e procedimento. Campinas: Pontes.

PESSOA, F. "Não sei quantas almas tenho". Disponível em: $<$ http://www.revista.agulha.nom.br/fpesso35.html> Acesso em: 15/02/2009.

REIS, V. S. (2006a). Representações Identitárias Em Diários De Aprendizagem De Inglês Como LE. In: SEVFALE - SEMANA DE ATIVIDADES ACADÊMICAS ESPECIAIS: Ensino, Pesquisa e Extensão, 6, Belo Horizonte. Anais... Faculdade de Letras da UFMG. CD-ROM. p. 1-15.

. (2006b). Análise das Representações Em Diários de Alunos de Língua Estrangeira. In: ENCONTRO MINEIRO DE ANÁLISE DO DISCURSO: GÊNEROS, COMUNICAÇÃO E SOCIEDADE, 1, 2006b, Belo Horizonte. Anais... Faculdade de Letras da UFMG. CD-ROM. p. 1-13.

(2007). O diário de aprendizagem de língua estrangeira (inglês) sob a perspectiva do processo discursivo. 143 f. Dissertação (Mestrado em Lingüística Aplicada ao Ensino de Línguas) - Faculdade de Letras, Universidade Federal de Minas Gerais, Belo Horizonte.

. (2010). O professor (de LE) e o formador em (um) projeto de educação continuada: as (in)certezas dessa/nessa relação. In: VIANA, V.; MILLER, I. K. (org.). CONGRESSO LATINO-AMERICANO DE FORMAÇÃO DE PROFESSORES DE LÍNGUAS - CLAFPL, 2, Anais... Rio de Janeiro: Letra Capital, PUC-Rio, p. 803-820.

REVUZ, C. (1998). A língua estrangeira entre o desejo de um outro lugar e o risco do exílio. In: SIGNORINI, I. (org.) Lingua (gem) e Identidade. Campinas: Mercado de Letras, p. 213-230.

ROUDISNESCO, E.; PLON. M. (1944). Dicionário de Psicanálise. Trad. Vera Ribeiro; Lucy Magalhães. Rio de Janeiro: Jorge Zahar Ed., 1998.

SAGOR, R. (1993). How to conduct collaborative action research. Alexandra: Virginia ASCD.

SERRANI, S. (1993). A Linguagem na Pesquisa Sociocultural: Um estudo da repetição na discursividade. Campinas: Ed. da UNICAMP.

SERRANI-INFANTE, S. M. (2001). Ressonâncias discursivas y cortesia em prácticas de lecto-escritura. D.E.L.T.A., v. 17, n. 1, p. 31-58. 
REIS, SILVA e TORRES - Teorizando a prática ou praticando a teoria...

VOLKMANN, M. J.; ANDERSON, M. A.( 1998). Creating a professional identity: Dilemmas and metaphors of a first-year chemistry teacher. Science Education, 82, p. 293-310.

Recebido: 24/08/2009

Aceito: 11/04/2011 